\title{
Aspects of ascites
}

\author{
ROBIN KNILL-JONES \\ M.A., M.B., B.Chir., M.R.C.P.
}

\begin{abstract}
Ascites has long been known to be associated with liver disease and was first recorded by Erasistratus in 304 B.C. (Rolleston \& McNee, 1929). Early experimental work on the production of ascites by occlusion of the thoracic vena cava was done by Richard Lower in the Eighteenth Century (Bolton, 1904).
\end{abstract}

\section{The mechanism}

The production of ascitic fluid is still incompletely understood although a number of factors have been shown to be associated with its formation. According to Starling's law either a rise in pressure in the capillaries of the portal circulation or a fall in albumin concentration could result in an increased transudation. In animal experiments it has been shown that both factors must be present to produce ascites. In dogs a rise in portal pressure from ligation of the portal vein does not result in ascites and neither does it form in dogs made hypoalbuminaemic by plasmapheresis. Both procedures together produce gross ascites (Berman \& Hull, 1952).

In man, obstruction to the portal vein will only occasionally produce ascites in the absence of hypoalbuminaemia. In forty-six cases of extrahepatic portal vein obstruction a history of ascites was found in twelve. In eight of these the ascites was transient and associated with portal septicaemia or gastro-intestinal haemorrhage where albumin levels were likely to be reduced temporarily. In four, however, there was persistent ascites in the presence of a normal serum albumin (Thompson, Williams \& Sherlock, 1964). Similar findings have been reported recently (Stathers, Ma \& Blackburn, 1968).

In established cirrhosis both factors are present. The hypoalbuminaemia results partly from reduction in albumin synthesis and partly from haemodilution; the albumin being distributed in an increased extracellular fluid, particularly when ascites is present. Attempts to show a critical level of albumin concentration below which ascites forms have been unsuccessful. However, if the degree of portal hypertension as shown by the intrasplenic pressure is also considered, a more accurate dividing line between those with, and those without ascites can be shown (Atkinson \& Losowsky, 1961).

\section{Other factors}

As a consequence of portal hypertension there is an increased formation of lymph in the liver. Lymph flow into the thoracic duct is considerably increased. There appears to be a limit to flow through the junction of the thoracic duct and subclavian vein (Lachapèle \& Lacoste, 1964), and a rise in lymph pressure can be demonstrated. The lymphatic system dilates and congested lymphatics have been shown in the hilum of the liver in patients with cirrhosis coming to post-mortem (Baggenstoss \& Cain, 1957). The excess lymph which cannot be removed via the thoracic duct 'weeps' from the surface of the liver, probably the major site of production of ascitic fluid. This can be shown experimentally in dogs by transferring the liver above the diaphragm and tying the hepatic veins. A hydrothorax forms quickly (Free man, 1953). Production of ascites in dogs by suprahepatic venous occlusion can be prevented by a preliminary operation to bypass the lymphaticovenous junction (Dumont $\&$ Witte, 1966).

Another important factor is a high level of circulating aldosterone, which results in the daily sodium excretion in the urine being $1 \mathrm{mEq}$ or less. The high levels of aldosterone are due largely to a raised secretion rate from the adrenals (Laragh, 1962). Decreased inactivation by the damaged liver has also been suggested.

The cause of the raised aldosterone secretion rate is not understood. In normal subjects the stimulus can be sodium depletion, reduction in blood volume or reduction in renal blood flow (Peart, 1965). In cirrhotic patients with ascites total body sodium is increased (Casey, Summerskill \& Orvis, 1965) and so also is the blood volume, at least at the stage they present to a doctor. However, renal blood flow may be reduced in spite of a normal or raised cardiac output (Lancestremere et al., 1962) and this could activate the renin-angiotensin system which in turn stimulates aldosterone production. Renin levels have been shown to be greatly raised in patients with ascites (Brown et al., 1964) and the juxtaglomerular apparatus is hypertrophied (Reeves, Lowenstein \& Sommers, 1963). Alternatively a 'volume receptor' may exist in a site which is relatively dehydrated by the continual loss of fluid into the peritoneal cavity. 
In the dog experimental studies suggest the presence of a receptor in the liver which is responsible for the stimulus to aldosterone production (Orloff et al., 1964).

Finally there is conflicting evidence regarding anti-diuretic hormone in cirrhosis (Bernstein et al., 1953; Lee \& Bisset, 1958). If levels are raised, this would further increase water retention and also account for the abnormal handling of water in cirrhosis.

\section{Treatment}

The treatment of a patient with active cirrhosis and ascites is illustrated by Fig. 1. Immediately on admission he was put on a low sodium diet of about

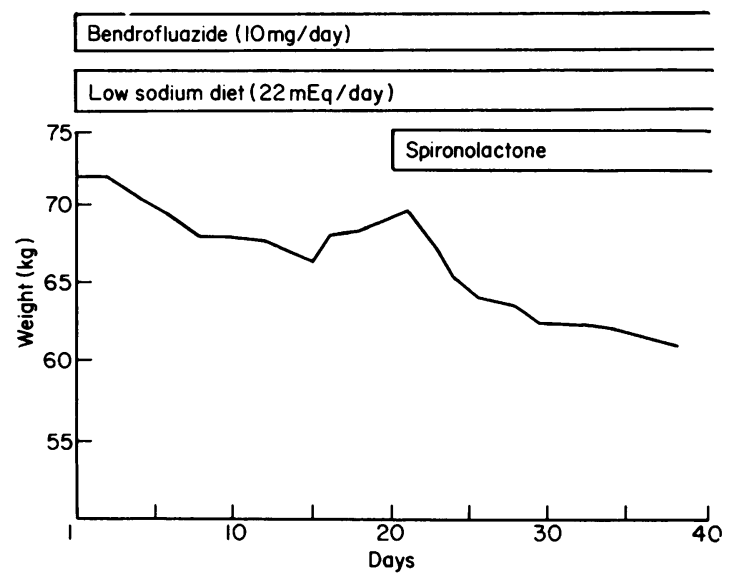

FIG. 1. Treatment of a patient (O.S.) with ascites.

$22 \mathrm{mEq}$, and arrangements made for daily weighing. This is a far better guide to fluid balance than input/ output charts. Bendrofluazide was also started (preferably after an initial control period) and with it potassium supplementation in doses of 50-100 $\mathrm{mEq}$ daily. This is essential, as in addition to the potassium loss induced by diuretic therapy, total body potassium may be reduced from the hyperaldosteronism already mentioned. Choice of potassium preparation lies between the effervescent BP tablet, containing potassium bicarbonate, or one of the newer preparations which contain potassium chloride; for example: Kloref, Camcopot or Slow-K. Chloride is important as it alone can correct the alkalosis associated with potassium deficiency (Kassirer \& Schwartz, 1966). Hypokalaemic alkalosis is not uncommon in patients with severe hepatic dysfunction and is probably responsible for their inability to retain potassium supplements (Casey et al., 1965; Sherlock et al., 1966).

This regime resulted in an initial loss of weight, but it then rose and spironolactone was given to block the renal action of aldosterone. After the usual short delay of 2-3 days weight fell steadily and ascites resolved.

Some of the various diuretics available together with the yearly hospital cost for a patient on an average dose are shown in Table 1 . They can be conveniently divided into two groups. The first

TABle 1. Cost of diuretic therapy (for average dose)

\begin{tabular}{lrl}
\hline Diuretic treatment & $\begin{array}{c}\text { Hospital cost } \\
\text { per patient-year }\end{array}$ \\
\hline 1. Potassium-losing & & \\
Bendrofluazide & $£ 2 ~$ & $2 \mathrm{~s}$. \\
Frusemide & $£ 9$ & $2 \mathrm{~s}$. \\
Ethacrynic acid & $£ 11 \mathrm{l}$ s. \\
2. Potassium-retaining & \\
Triamterene & $£ 8 \mathrm{ls}$. \\
Spironolactone & $£ 26$ & $11 \mathrm{~s}$. \\
Amiloride* & $£ ?$ \\
\hline * Only available for clinical trial.
\end{tabular}

group comprises those that act on the proximal tubule. Bendrofluazide is the mildest and has a medium duration of action. Frusemide is more powerful but short-acting. In the more resistant cases ethacrynic acid can be used, beginning with a low dose $(25 \mathrm{mg})$ and gradually working up to $100 \mathrm{mg} /$ day, if needed. Unfortunately the more powerful the diuretic, the more likely it is to produce potassium depletion and precipitate encephalopathy, so that serum electrolytes should be estimated on alternate days.

The diuretics in the second group act on the distal tubule and conserve potassium. They are usually given in combination with one of the first group. Triamterene acts in this way but is not an aldosterone antagonist, unlike spironolactone which blocks the action of aldosterone on the distal tubule. Amiloride (M.K.870) has been introduced recently, but as with others of this group it should be used in combination with one of the first group, initially in a dose of 10 $\mathrm{mg}$ /day (Senewiratne \& Sherlock, 1968).

Hyponatraemia occurs not uncommonly during treatment. The hyponatraemia is usually due to the 'sick cell syndrome' where sodium moves into cells which are unable to remove it. This is normally a reflection of severe hepatic failure. It is occasionally due to a rapid diuresis of sodium in a patient on a low sodium diet. In both cases total body sodium is raised and only very occasionally is infusion of hypertonic saline of value. Mannitol infusion can be used as an osmotic diuretic to remove water and improve serum sodium levels. It may also be used to increase free water clearance and initiate a diuresis in a resistant case.

Human salt-free albumin in intravenous doses of 25-50 g daily has also been used as a temporary measure to initiate a diuresis (Wilkinson \& Sherlock, 
1962). Its effect is usually short-lived as albumin diffuses rapidly into ascitic fluid.

Prednisone therapy is occasionally of value. It increases free water clearance and like mannitol is of value in dilutional hyponatraemia. Prednisone also produces a paradoxical loss of sodium in spite of its more normal sodium-retaining activity (Stormont et al., 1959). Long courses are dangerous because of the incidence of fatal infections in debilitated patients.

\section{Uses of surgery}

Many operations have been devised and fallen into disrepute. At present the place for using a peritoneal-atrial shunt needs further assessment. The principle of a one-way valve and a subcutaneous 'balloon' for manual pumping inserted under local anaesthesia has been shown to remove ascites and to remain patent in a small group of patients (Hyde \& Eiseman, 1967). Direct cannulation of the thoracic duct under local anaesthesia also produces a reduction of ascites in some patients (Dumont \& Mulholland, 1960). Fish and colleagues (1968) showed, however, that in four patients with lymph drainage there was no change in salt or water balance with or without reinfusion of lymph unless it was dialysed to remove salt and water. A portacaval shunt, by reducing portal venous pressure may also relieve ascites, although the operative mortality in patients with this degree of hepatic decompensation is high.

Finally it must be stressed that therapeutic paracentesis as opposed to a diagnostic tap for cells, protein and organisms, is rarely necessary now that powerful diuretics are available. It results in a significant loss of albumin and may also adversely affect splanchnic and renal haemodynamics, apart from the danger of introducing infection. It is as well to remember also that the patient may be more comfortable if not dried out completely. As others have said, this may be summarized as 'better wet and alive, than dry and dead'.

\section{References}

Atkinson, M. \& Losowsky, M.S. (1961) The mechanism of ascites formation in chronic liver disease. Quart. J. Med. N.S., 30, 153.

Baggenstoss, A.M. \& CAIN, J.C. (1957) The hepatic hilar lymphatics of man. New Engl. J. Med. 256, 531.

BeRMAN, J.K. \& Hull, J.E. (1952) Experimental ascites. Its production and control. Surgery (St Louis), 32, 67.

Bernstein, S.H., Weston, R.E., Ross, G , Grossman, J., Hanenson, I.B. \& Leiter, L. (1953). Studies on intravenous water diuresis and nicotine and pitressin antidiuresis in normal subjects and patients with liver disease. J. clin. Invest. 32, 422.

Bolton, C. (1904) The experimental production of uncomplicated heart disease with especial reference to the pathology of dropsy. J. Path. Bact. 9, 67.

Brown, J.J., Davies, D.L., Lever, A.F. \& Robertson, J.S. (1964) Variations in plasma renin concentrations in several physiological and pathological states. Can. med. Ass. J. 90, 201.

CASEY, T.H., Summerskill, W.H.J. \& ORVIS, A.L. (1965) Body and serum potassium in liver disease. Gastroenterology, 48, 198.

Dumont, A.E. \& Mulholland, J.H. (1960). Flow rate and composition of thoracic duct lymph in patients with cirrhosis. New Engl. J. Med. 263, 471.

Dumont, A.E. \& WitTe, M.H. (1966) Significance of excess lymph in the thoracic duct in patients with hepatic cirrhosis. Amer. J. Surg. 112, 401.

Fish, J.C., Sarles, H.E., Remmers, A.R. \& Williams, R.D. (1968) Effect of thoracic duct decompression on ascites. J. Amer. med. Ass. 203, 98.

Freeman, S. (1953) Recent progress in the physiology and biochemistry of the liver. Med. Clin. N. Amer. 37, 109.

Hyde, G.L. \& Eiseman, B. (1967) Peritoneal atrial shunt for intractable ascites. Arch. Surg. (Chic.), 95, 369.

Kassirer, J.P. \& SCHWARTZ, W.B. (1966) Correction of metabolic alkalosis in man without repair of potassium deficiency. Amer. J. Med. 40, 19.

LACHAPÈle, A.-P. \& LACOSTE, G. (1964) First results obtained in the study of the kinetics of the distal part of the thoracic duct in the alive human subject. Presse Méd. 72, 2133.

Lancestremere, R.G., Davidson, P.L., Earley, L.E., O'Brien, F.J. \& PAPPER, S. (1962) Renal failure in Laennec's cirrhosis. II. Simultaneous determination of cardiac output and renal haemodynamics. J. clin. Invest. 41, 1922.

LARAGH, J.H. (1962) Hormones and pathogenesis of congestive heart failure: vasopressin, aldosterone and angiotensin. II. Further evidence for renal-adrenal interaction. Studies in hypertension and cirrhosis. Circulation, 25 1015.

LEE, J. \& BISSET, G.W. (1958) The secretion of neurohypo physial hormones in man with special reference to livef disease. Proc. roy. Soc. Med. 51, 361.

Orloff, M.J., BadDeley, R.M., Ross, T.H., Nutting, R.O., Halasz, N.A. \& NeESBY, T. (1964) Regulation of aldosterone secretion by an hepatic receptor. Surg. Forum, 15, 74.

Peart, W.S. (1965). The renin-angiotensin system. Pharmacol. Rev. 17, 143.

Reeves, G., Lowenstein, L.M. \& Sommers, S.C. (1963) The macula densa and juxtaglomerular body in cirrhosis. Arch. intern. Med. 112, 708.

Rolleston, Sir H. \& McNee, J.W. (1929) Diseases of the Liver, Gall Bladder and Bile Ducts, 3rd edn, p. 270. Macmillan, London.

Senewiratne, B. \& Sherlock, S. (1968) Amiloride ('M.K.870') in patients with ascites due to cirrhosis of the liver. Lancet, i, 120.

Sherlock, S., Senewiratne, B., Scott, A. \& Walker, J.G. (1966) Complications of diuretic therapy in hepatic cirrhosis. Lancet, i, 1049.

Stathers, G.M., MA., M.H. \& Blackburn, C.R.B. (1968) Extrahepatic portal hypertension. The clinical evaluation, investigation and results of treatment in 28 patients. Aust. Ann. Med. 17, 12.

Stormont, J.M., Crabbe, J., Fast, B., Wolfe, S.J. \& Davidson, C.S. (1959) The effect of prednisone and amphenone on fluid and electrolyte balance, and on aldosterone excretion of patients with cirrhosis and ascites. J. Lab. clin. Med. 53, 396.

Thompson, E.N., Williams, R. \& Sherlock, S. (1964) Liver function in extrahepatic portal obstruction. Lancet ii, 1352.

Wilkinson, P. \& SHerlock, S. (1962) The effects of repeated albumen infusions in patients with cirrhosis. Lancet, ii, 1125. 